\title{
Evaluation of Micro EV's Spreading to Local Community by Multinomial Logit Model
}

\author{
Yoichi Seki* \\ Department of Computer Science, Gunma University, Kiryu, Japan \\ Luis C. Manrique \\ Graduate School of Information Systems, The University of Electro-Communications, Tokyo, Japan \\ Kenji Amagai \\ Department of Mechanical System Engineering, Gunma University, Kiryu, Japan \\ Takayuki Takarada \\ Department of Chemical and Environmental Engineering, Gunma University, Kiryu, Japan
}

(Received: February 15, 2012 / Revised: April 24, 2012 / Accepted: April 25, 2012)

\begin{abstract}
Micro Electric Vehicles are considered as a solution for reducing $\mathrm{CO}_{2}$ emissions, however, it is difficult to evaluate its impact in a local community when it has been introduced. In this study, we evaluated how to spread the Micro EV within the community, using the utility derived from a multinomial logit model, and analyze the effect on $\mathrm{CO}_{2}$ emissions. The householder's utility model is based on an investigation about Kiryu citizen's activities of shopping, transportation methods, etc. Using the geographic information system, we get the distances of each householder and the stores, and estimate a multinomial logit model about the combination choices of shopping stores and transportation method.
\end{abstract}

Keywords: Multinomial Logit Model, Direct Product Alternatives, Utility, $\mathrm{CO}_{2}$ Emission, Geographic Information System, Data Mining

* Corresponding Author, E-mail: seki@cs.gunma-u.ac.jp

\section{INTRODUCTION}

Japanese society has two issues for sustainability. One is the rapid aging of population, especially, in local cities where this issue is severe as shown in Figure 1, because young persons tend to leave for larger cities. It has resulted in the decay of urban area of the local small cities, along with the exodus of young residents from the inner cities to the suburbs of the cities during the period of rapid economic growth in the postwar era of Japan. The spread population gives rise to operational difficulties of public transportations in local cities. Under these circumstances, most of the residents in local city use his/ her private automobiles for daily short trips. The other issue is the energy-saving for anti-global-warming. To resolve this issue, it is needed to reduce $\mathrm{CO}_{2}$ emissions, that is, to save fossil fuel. However, automobiles consume much more fossil fuel than public transportation methods.

One of the solutions is a multimodal urban region (Bertolini and Clercq, 2003). Combined use of public transformation methods for longer trips and personal transportation methods for shorter trips produces a lowcarbon society. Micro electric vehicles (micro EV's) are considered as one method for personal transformation in this scenario. Micro EV is an EV for one personal use. It has small and light body, low speed, and has characteristics of an automobile and a bicycle. It is easy even for 
elderly persons to drive, and its energy can be supplied from solar energy (Toshio, 2011). From December 2011, use of micro EV was demonstrated in Kiryu, a local city in Japan, founded by the Minister of Land, Infrastructure, Transportation and Tourism (MLIT, 2010; Hada, 2009).

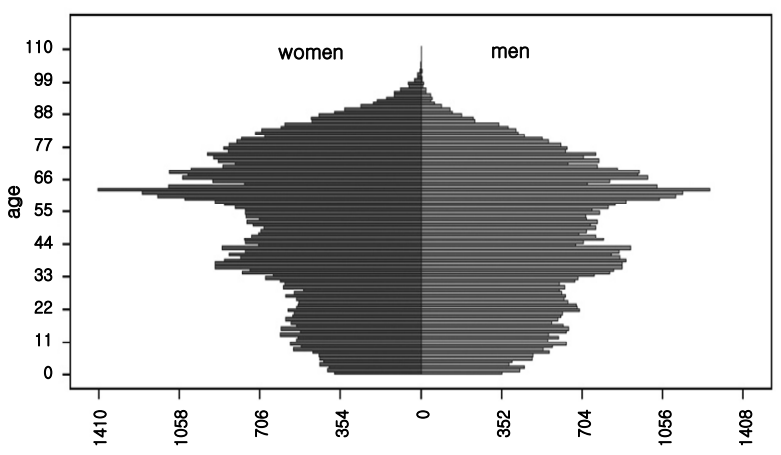

Figure 1. Population pyramid of Kiryu city.

However, it is difficult to evaluate its impact in a local community when it has actually been introduced. In this study, we evaluated how to spread the micro EV within the community, using the utility derived from the multinomial logit model and analyzed the effect on $\mathrm{CO}_{2}$ emissions.

First, we propose a generalization of multinomial logit model (Ben-Akiva and Lerman, 1995; Train, 2009) for direct product alternatives of shopping stores and transportation methods to the stores. Using a result of questionnaire survey, we estimate this model, and clarify the utility structure for the combination of shopping store and transportation method. This model explains discrete choices of combinations according with other variables such as distance to the store, his/her age, etc.

Next, we assume some conditions of utility of micro EV's, and estimate the probability of citizens' choices of the combinations. This new method was added as a new choice of transportation. From this probability, we estimate $\mathrm{CO}_{2}$ emissions for shopping trips in Kiryu city.

Our approach in this paper may be used for evaluating how widely a new technology can be spread to a society, and be able to forecast the demand level in the saturated case.

\section{MULTINOMIAL LOGIT MODEL FOR DIRECT PRODUCT ALTERNATIVES}

\subsection{Multinomial Logit Model}

The multinomial logit model is one of discrete choice models which explain the probabilities to select alternatives in a finite choose set $\mathrm{C}$. These models assume that alternatives in the choice set are mutually exclusive, ex- haustive. Based on the utility-maximizing theory that states that decision maker chooses the alternative which maximizes his/her utility, the probability that decision maker $i$ choose an alternative $c$ is

$$
\begin{aligned}
P_{i c} & =\operatorname{Prob}\left(U_{i c}>U_{i c^{\prime}}, \forall c^{\prime} \neq c\right) \\
& =\operatorname{Prob}\left(V_{i c}+\varepsilon_{i c}>V_{i c^{\prime}}+\varepsilon_{i c^{\prime}}, \forall c^{\prime} \neq c\right)
\end{aligned}
$$

where $U_{i c}$ is the utility of the alternative $c$ for the decision maker $i$. $V_{i c}$ is a representative part of $U_{i c}$, which is the function of attributes of the alternative $c$ and the decision maker $i . \varepsilon_{i c}$ is a random part of $U_{i c}$, which summarizes the contribution of unobserved variables and distributes independently and identically extreme value distribution. We can find the closed form of the probability as the Eq. (2).

$$
P_{i c}=\frac{\exp \left(V_{i c}\right)}{\sum_{c^{\prime} \in C} \exp \left(V_{i c^{\prime}}\right)}
$$

If we observe $K+K$ ' attributes from the alternatives and the decision makers, and among them, $K$ attributes are categorical factor attributes and $K^{\prime}$ attributes are continuous variables $x_{k^{\prime} i c}$. We usually formulate the function $V_{i c}$ of attributes as Eq. (3), for example, in the regression model.

$$
V_{i c}=\beta_{0}+\sum_{k=1}^{K} \beta_{k l_{k i c}}+\sum_{k^{\prime}=1}^{K^{\prime}} \beta_{k^{\prime}} x_{k^{\prime} i c}
$$

where $\beta_{0}$ is the intercept constant, $\beta_{k l}$ 's and $\beta_{k^{\prime} l}$ 's are the coefficients for the attributes of the categorical factor and the continuous variables, respectively. $l_{k i c}$ is the level of the $k^{\text {th }}$ factor attribute of choice ic and $x_{k^{\prime} i c}$ is the value of $k^{\text {th }}$ continuous attribute of choice $i c$. However, in the multinomial logit model, $\beta_{0}$ and one of the $\beta_{k l}$ 's for each $k$ must be set 0 , to avoid the indetermination of coefficients because of equivalent ratio of Eq. (3) between the choices. In this paper, we set $\beta_{k l}=0$, i.e., the coefficients of the first categories are set zero.

\subsection{The Model for Direct Product Alternatives}

The choice set of the multinomial logit model is a direct product of two sets, for example, set of shopping stores and the set of transportation methods. Let the two sets be $\mathrm{S}$ and $\mathrm{T}$. The choice set is $\mathrm{C}=\{(s, t) \mid s \in \mathrm{S}, t \in$ $\mathrm{T}\}$. In this example, a decision maker chooses a combination of shore $s$ and transportation method $t$ to the selected store. Utilities are defined for the combinations.

Estimation method of the model is the same for the most part to ordinary logit model. However, we need some attention to parameterization of coefficients. Because utility is a latent index, and its values are relative in each decision maker, we must set coefficients of base categories to zero, as mentioned above. So attributes of the two sets are parameterized, as setting their coeffi- 
cients of first categories to zero, respectively. Furthermore, if we need to estimate any interaction term that includes two attributes, the coefficient of the interaction whose level is the first category, at least in one attribute, must be set zero. An example of this formulation is given in section 4 .

\section{SURVEY IN KIRYU CITY}

The information needed for estimation of the model is based on a survey conducted in Kiryu in October 2009. Kiryu is a local city in Gunma prefecture, and is located about $100 \mathrm{~km}$ north of Tokyo.

This study is part of the main project "Construction of the town of Kiryu for the future with anti-globalwarming through the regional power" supported by Japan Science and Technology Agency, and the main goal is to reduce $80 \%$ of $\mathrm{CO}_{2}$ emitted in the city. We research to understand the effect of modal shift of shopping from the information given on the questionnaires.

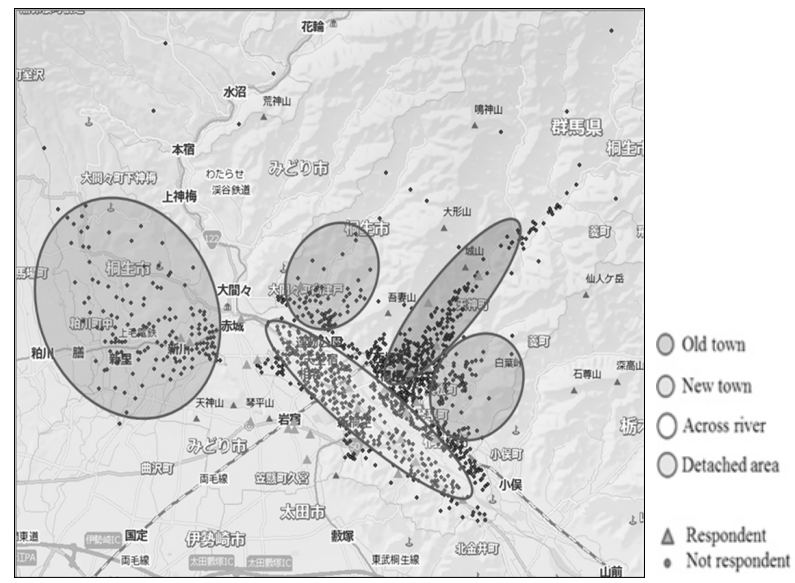

Figure 2. Areas of Kiryu city and sampled householders.

This questionnaire was sent to random sampled 10,000 householders from a total of 50,163 household- ers of Kiryu and returned 2,269 questionnaires; it means the $4.52 \%$ of the total or the $22.69 \%$ of the sample. We divided Kiryu city into 4 areas in order to analyze the relationships between them. These areas are represented as: old town, new town, across river, and detached area in Figure 2.

In this survey, we asked about shopping to the main person who usually goes to shopping in his/her home. The main part of the question is about the frequency per month. We must specify the visited store to obtain the distance from his/her home. However, it is too difficult to ask all of the stores located in Kiryu city. For that reason, we limited alternatives in the questionnaire to the representative shopping places in Kiryu. We have selected 41 representative stores and shopping areas in/near the city, and we have selected some shopping activities done in the store, such as: foods, clothes, daily goods, window-shopping, etc. The frequencies are asked for every store and for every kind of shopping activity. In addition with these frequencies, we asked about the means of transportation used to go to every store. The categories of transportation are bicycle, car, bus, train, and non use (walk).

In addition, we surveyed the demographic information of the respondents; sex, age, location, whether he/ she had a car license.

We used a geographic information system (ArcGIS ver. 9.5; Esri, Redlands, CA, USA) to get the location of each householder and the stores from their addresses, and also to get the Euclidean distance between them.

\section{ESTIMATION OF SHOPPING TRIP UTILITY}

In this paper, we restrict the kind of shopping activity to food shopping, which is the most frequent activity, and estimate a multinomial logit model for alternatives which are direct product of set of shopping stores and the set of transportation methods. The set of stores are 12 shopping places as listed in Table 1 . These places are

Table 1. Shopping places investigated

\begin{tabular}{|c|c|c|c|}
\hline Name & Location & Abbreviation & No. of places \\
\hline $\begin{array}{ll}1 \text { Old shopping street } \\
\end{array}$ & Old town & $\begin{array}{ll}\text { Old-st } \\
\end{array}$ & 2 areas \\
\hline 2 Large-scall retail store & Old town & LS & 1 shop \\
\hline 3 Supermarket $\mathrm{C}$ & Old town/across river & SM-C & 3 shops \\
\hline 4 Supermarket R & Old town/across river & SM-R & 3 shops \\
\hline 5 Supermarket $\mathrm{F}$ & Across river & SM-F & 1 shop \\
\hline 6 Supermarket V & all area except across river & SM-V & 3 shops \\
\hline 7 Supermarket $\mathrm{P}$ & Across river & SM-P & 1 shop \\
\hline 8 Supermarket B & New town & SM-B & 2 shops \\
\hline 9 Shopping mail S & Detached area & M-S & 1 mall \\
\hline 10 Shopping mail Y & Across river & $\mathrm{M}-\mathrm{Y}$ & 1 mall \\
\hline 11 Large-scall shopping mail S & Outskirt of the city & LM-S & 1 mall \\
\hline 12 Large-scall shopping mail A & Outskirt of the city & LM-A & 1 mall \\
\hline
\end{tabular}


selected from 41 stores as the stores selling foods, and all branches having the same name are summarized to one store.

Also, in the original data we have distinguished transportation methods: car, bus, train, and bicycle. Nevertheless, in order to reduce the number of categories that are few checked, we have created a new transportation category called public transportation, it takes into account the information about bus and train. We consider that the respondent who checked no transformation method walks to the store, and we merge this case to the bicycle. Finally, we distinguish three transportation methods; walk/bicycle, public transportation, and car.

Our dataset consists of 4,871 selected alternatives that are selected by 1,618 householders. It means that each householder selects 3.01 pairs of stores and methods from $12 \times 3=36$ pairs on average. For each selected alternative, numbers of trips in the month are observed; the total of these numbers is 26,092 times.

Using the above data set, we developed different kind of models, which explain the representative utility by 5 attributes and the interactions between them and choices. The used attributes are distance to the store and age, sex, place area, car license status of respondents. Estimated models are evaluated by Akaike information criteria (AIC). From these results, we select the next model.

$$
\begin{aligned}
V_{i s t}= & \beta_{1 t}+\beta_{2 s}+\beta_{3} \log \left(d_{i s}\right)+\beta_{4 t} \log \left(d_{i s}\right)+\beta_{5 t t_{i}} \\
& +\beta_{6 t} A_{i}+\beta_{7 t_{i}}+\beta_{8 t} O_{s}+\beta_{9 s} A_{i}
\end{aligned}
$$

where

$i$ : Householder.

$s: \quad$ Store choice. $s \in$ \{old town shopping area, supermarket $1, \cdots, 9$, huge shopping mall 1,2$\}$

$t: \quad$ Transportation method choice.

$V_{\text {ist }}$ : Utility of visit to store $s$ by the method $t$ for the individual $i$.

$d_{i s}:$ Distance from the home $i$ to the store $s$.

$A_{i}$ : Age of householder $i$.

$r_{i}$ : Place area where home of $i$ is located. $r_{i} \in$ \{old town, new town, across river, detached area $\}$.

$O_{s}: \quad$ Is store $s$ in old town. $O_{i} \in\{0,1\}$

$l_{i}$ : $\quad$ Car license status of householder $i . l_{i} \in\{$ hold, not hold

$\beta_{k}:$ Coefficient of $k^{\text {th }}$ attribute $\cdot$

The estimated coefficients for the model are shown in the Table 2.

First, effects related with the kind of transportation method are shown in the Figure 3. This figure indicates the effect to utility of distance from home $i$ to store $s$ and possession of driving license: $\beta_{1 t}+\left(\beta_{3}+\beta_{4 t}\right) \log \left(d_{i s}\right)+\beta_{5 t l}$ for each $t$ and $l$. For the trip less than $1.37 \mathrm{~km}$, for the average person who does not have a car driving license, walk/bicycle, car and public transformation have much utility in this order, and the opposite for the longer trip. However, checking the interaction between transporta- tion method and car license, if he/she has a car license, car's utility become higher $(+1.4)$, and public transportation's drop -1.85 . Accordingly, car drivers always have maximum utility for car in practical distance, and they don't tend to use public transportations. As for the effect of age to utility: $\beta_{6 t}$, elderly persons tend to avoid car driving.

Table 2. Estimated model coefficients

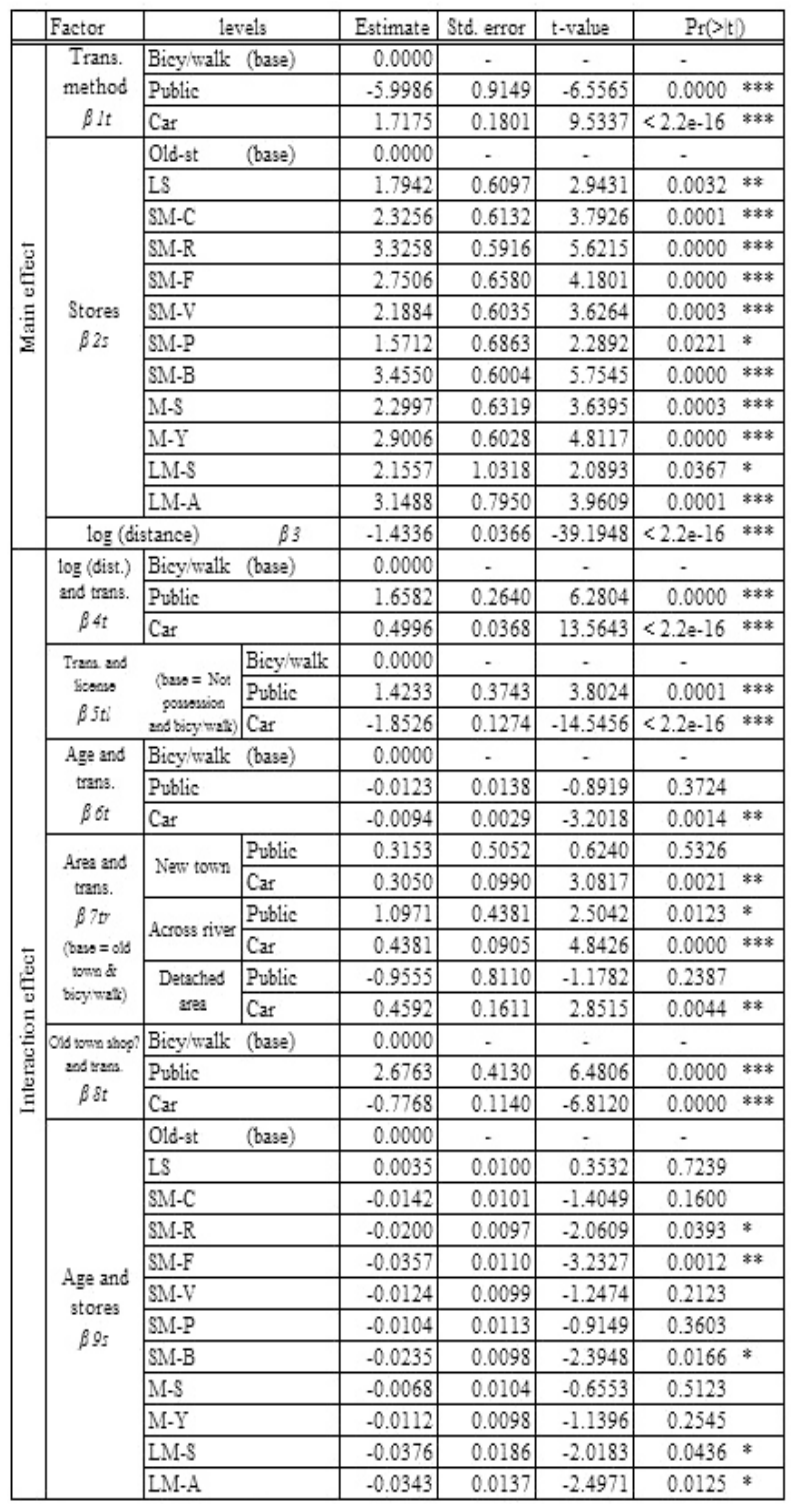

Signif. Codes: 0 “**, 0.001 “**, 0.1 “*, 0.05 '? 0.1 ' 1 .

Next, we consider the effect of areas. Householders residing in the new town or across river area tend to use some transportation method; public one or car, compared with old town and detached area. The reason is considered that four railways have come to Kiryu city, and they cover across river area and some part of the new city area. Furthermore, bus network covers these areas, though it is not so frequent. Householders in these 
areas, who need to trip longer distance than old town area, use the some transportation method. On the other hand, in the detached area, access to these transportation methods is inconvenient and the services are less frequent, so they depend on car self-sufficiently. We represent this effect by term $\beta_{7 t r}$.

With respect to the location of stores, we distinguish whether the store is in the old town. The result of estimated $\beta_{8 t}$ indicated that public transportation, not car, tends to be selected for the trips to the store in old town.

Finally, we confirm the effect of store: $\beta_{2 s}$ and $\beta_{9_{s}}$. Every store have higher utility than the old shopping street, and have higher utility to younger person, except for old-st and LS, that are located in the old town area.

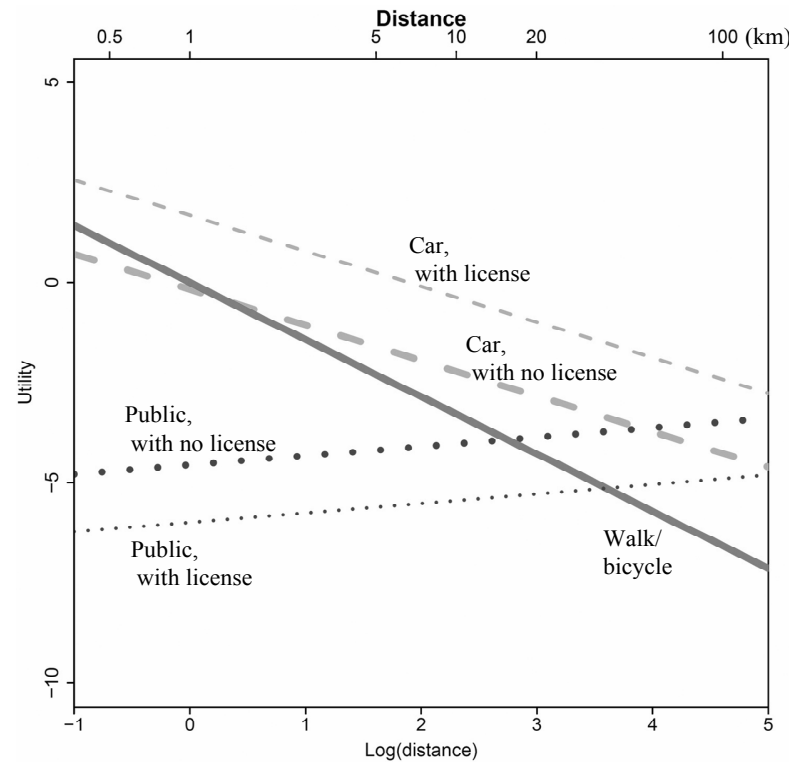

Figure 3. Utility function of moving distance of each transformation method.

\section{ESTIMATION OF $\mathrm{CO}_{2}$ EMISSION}

\subsection{How to Estimate the Spread of New Techno logy}

Once we have estimated utilities of alternatives for each householder, using the multinomial logit model, we can estimate any probability that a householder choices a alternative; a combination of a store and a transportation method. Adding some assumption about the utility of new technology, we can estimate the probability that the new technology is selected by each person.

In our case, we estimate the probabilities of micro EV in food-buying trip. To calculate the probability, we assume below assumptions:

- The utility of the micro EV is the mean of car and bicycle in every situation of householder $i$ and store $s$, as below equation. The utilities of the other methods are invariant under the introduction of the micro EV.

$$
V_{i s E V}=\left(V_{i s B i c y}+V_{i s C a r}\right) / 2
$$

- The citizens can buy this transportation method, if he/ she likes it.

- The citizens don't change the frequency of food-buying trip.

- The population volume and its demographic situation of the citizen will remain constant.

Once we could calculate the utility value of micro $\mathrm{EV}$, we can estimate the probability of each combination of store and method using Eq. (2). This calculation can be sound, if we could assume an appropriate condition to the utility of the new technology to the original state.

We have already one month frequency of foodbuying for each householder, so we can estimate expected frequency of the alternatives by multiplying the selection probability by the frequency. Each alternative; a trip to a store, has distance of trip. Therefore, we can estimate the one month accumulated trip distance of each householder for each transportation method. The results are listed in Table 3.

\subsection{Effect the Spread of Micro EV}

First, we see the trip distance per person in Table 3. In surveyed data, car distance is longest among all methods, and at old town it is shortest among the other areas. This feature is the same in the estimated result added micro EV.

After the introduction of micro EV, micro EV became the second method, and it is used in $24.8 \%$ of all trip in distance on the average weighted by number of persons. Car remains the first method, however, its use is reduced $20.9 \%$. Micro EV is used in old town most frequently, because of short mean distance of trips.

\subsection{Assessment of the Emission of $\mathrm{CO}_{2}$}

We assess the rough amount of $\mathrm{CO}_{2}$ emissions in Kiryu for food-buying in a year using Eq. (6).

$$
A_{s}=\frac{12}{0.04523} \sum_{i j m} d_{i j} n_{i j} r_{i j m} \rho_{m}
$$

where,

$i: \quad$ Householder.

$j: \quad$ Store

$m: \quad$ Transportation method

$d_{i j}: \quad$ Distance between $i$ and $j$.

$n_{i j}: \quad$ Frequency of visits in a month.

$r_{i j m}: \quad$ Ratio of visiting method $m$.

$\rho_{m}: \quad$ Methods $m$ 's average $\mathrm{CO}_{2}$ emission $(\mathrm{g} / \mathrm{km})$.

0.04523: Rate of respondents among all citizens.

12: Number of months in a year. 
Table 3. Impact of introduction micro electric vehicles (EV) to trip distance

\begin{tabular}{|c|c|c|c|c|c|c|c|c|c|c|c|c|}
\hline & \multicolumn{5}{|c|}{ Raw data } & \multicolumn{5}{|c|}{ Percentage } \\
\hline & & & $\begin{array}{l}\text { Old } \\
\text { town }\end{array}$ & $\begin{array}{l}\text { New } \\
\text { town }\end{array}$ & $\begin{array}{l}\text { Across } \\
\text { river }\end{array}$ & $\begin{array}{c}\text { Detached } \\
\text { area }\end{array}$ & $\begin{array}{c}\text { All } \\
\text { area }\end{array}$ & $\begin{array}{l}\text { Old } \\
\text { town }\end{array}$ & $\begin{array}{l}\text { New } \\
\text { town }\end{array}$ & $\begin{array}{l}\text { Across } \\
\text { river }\end{array}$ & $\begin{array}{c}\text { Detached } \\
\text { area }\end{array}$ & $\begin{array}{c}\text { All } \\
\text { area }\end{array}$ \\
\hline \multicolumn{3}{|c|}{ Number of persons } & 527 & 374 & 541 & 176 & 1618 & 32.57 & 23.11 & 33.44 & 10.88 & 100 \\
\hline \multicolumn{3}{|c|}{ Number of trip } & 8450 & 5828 & 8790 & 2255 & 25324 & 33.37 & 23.01 & 34.71 & 8.91 & 100 \\
\hline \multicolumn{3}{|c|}{ Total trip distance $(\mathrm{km} / \mathrm{mo})$} & 18105.39 & 15020.9 & 20035.45 & 8394.17 & 61555.90 & 29.41 & 24.40 & 32.55 & 13.64 & 100 \\
\hline \multirow{5}{*}{$\begin{array}{l}\text { Present } \\
\text { status } \\
\text { from } \\
\text { surveyed } \\
\text { data }\end{array}$} & \multicolumn{2}{|c|}{ Mean distance (km/trip) } & 2.14 & 2.58 & 2.28 & 3.72 & 2.43 & 88.14 & 106.03 & 93.77 & 153.12 & 100 \\
\hline & \multirow{4}{*}{$\begin{array}{l}\text { Trip distance } \\
\text { per person } \\
(\mathrm{km} / \mathrm{mo})\end{array}$} & Walk/bicy & 6.47 & 5.95 & 4.93 & 5.87 & 5.77 & 18.8 & 14.8 & 13.3 & 12.3 & 15.2 \\
\hline & & Public & 0.42 & 0.36 & 0.52 & 0.55 & 0.45 & 1.2 & 0.9 & 1.4 & 1.2 & 1.2 \\
\hline & & Car & 27.47 & 33.85 & 31.58 & 41.28 & 31.82 & 80.0 & 84.3 & 85.3 & 86.6 & 83.7 \\
\hline & & Total & 34.36 & 40.16 & 37.03 & 47.69 & 38.04 & 100 & 100 & 100 & 100 & 100 \\
\hline \multirow{7}{*}{$\begin{array}{l}\text { Status after } \\
\text { Intro-duction } \\
\text { of EV } \\
\text { estimated by } \\
\text { logit model }\end{array}$} & \multicolumn{2}{|c|}{ Total trip distance $(\mathrm{km} / \mathrm{mo})$} & 18009.57 & 15749.5 & 18311.15 & 9524.86 & 61595.07 & 29.24 & 25.57 & 29.73 & 15.46 & 100 \\
\hline & \multicolumn{2}{|c|}{ Mean distance (km/trip) } & 2.13 & 2.70 & 2.08 & 4.22 & 2.43 & 87.62 & 111.10 & 85.65 & 173.64 & 100 \\
\hline & \multirow{5}{*}{$\begin{array}{c}\text { Estimated trip } \\
\text { distance per } \\
\text { person } \\
(\mathrm{km} / \mathrm{mo})\end{array}$} & Walk/bicy & 4.89 & 4.32 & 3.53 & 5.49 & 4.37 & 14.3 & 10.3 & 10.4 & 10.2 & 11.5 \\
\hline & & Public & 0.24 & 0.30 & 0.47 & 0.54 & 0.36 & 0.7 & 0.7 & 1.4 & 1.0 & 1.0 \\
\hline & & Car & 20.08 & 27.27 & 21.68 & 35.01 & 23.90 & 58.8 & 64.8 & 64.0 & 64.7 & 62.8 \\
\hline & & EV & 8.97 & 10.21 & 8.17 & 13.08 & 9.44 & 26.2 & 24.3 & 24.1 & 24.2 & 24.8 \\
\hline & & Total & 24.17 & 42.11 & 33.85 & 54.12 & 38.07 & 100 & 100 & 100 & 100 & 100 \\
\hline
\end{tabular}

It is difficult to assess precisely Eq. (6), because we do not have precise information about the type of transportation method, for example, fuel consumption of householders' cars. So, we use the representative value shown in Table 4. In this table the emissions related with bicycle for $\mathrm{CO}_{2}$ are 0 , because it does not use any fuel. For the public transportation, we use the value of bus as a leading method. As to this value, we assume an average number of passengers equal to 10 , and divide the value 403.1 in Table 4 by 10 . As to the micro EV, it is also difficult to assess its $\mathrm{CO}_{2}$ emission (De Boncourt, 2011), we assume that its emission rate is estimated at $1 / 20$ of car's one.

Table 4. $\mathrm{CO}_{2}$ emissions rate

\begin{tabular}{|lc|}
\hline Transportation method & $\mathrm{CO}_{2}$ emissions $\left(\mathrm{gCO}_{2} / \mathrm{km}\right)$ \\
\hline \hline Car & $137.3^{\mathrm{a})}$ \\
Bus & $403.1^{\mathrm{b})}$ \\
Bicycle & 0. \\
Micro electric vehicles & 4.84 \\
\hline
\end{tabular}

a) $2.32 \mathrm{tCO}_{2} / \mathrm{kL} / 16.9 \mathrm{~km} / \mathrm{L} \times 1000$ (Ministry of the Environment, 2011; Japan Automobile Manufacturers Association Inc., 2011).

b) $2.58 \mathrm{tCO}_{2} / \mathrm{kL} / 6.4 \mathrm{~km} / \mathrm{L} \times 1000(\mathrm{ME}, 2011)$. The fuel consumption is a value of bus (Hino type HA6JLAE) that are used in Kiryu city.

Using above assumptions, we assess the amount of $\mathrm{CO}_{2}$ emission in Kiryu city at 188.3 (t/year) after micro EV was introduced, against 142.3 ( $\mathrm{t} /$ year) in the present situation. This is 46.0 ( $\mathrm{t}$ /year) $(24.4 \%)$ reductions as indicated in Table 5. Emission per person is smallest in old town, and is largest in detached area. Furthermore, in detached area, where population is sparse and residents need long trips for living, the emission does not reduce so much after the introduction of EV. Therefore, it is important for anti-global-warming to construct compact city, where almost residents live in a compact area in the city, and move by bicycle or energy-saving EV.

Table 5. Amount of $\mathrm{CO}_{2}$ emission and reduction

\begin{tabular}{|ccrrrrr|r|}
\hline & & $\begin{array}{c}\text { Old } \\
\text { town }\end{array}$ & \multicolumn{2}{c}{$\begin{array}{c}\text { New } \\
\text { town }\end{array}$} & $\begin{array}{c}\text { Across } \\
\text { river }\end{array}$ & $\begin{array}{c}\text { Detached } \\
\text { area }\end{array}$ & Total \\
\hline \hline \multirow{3}{*}{$\begin{array}{c}\text { Total } \\
(\mathrm{t} / \mathrm{yr})\end{array}$} & Emission & present & 53.0 & 46.3 & 62.5 & 26.6 & 188.3 \\
\cline { 2 - 8 } & & after EV & 38.9 & 37.5 & 43.2 & 22.7 & 142.3 \\
\cline { 2 - 8 } & Reduction & 14.0 & 8.8 & 19.3 & 3.9 & 46.0 \\
\hline \multirow{2}{*}{$\begin{array}{c}\text { Per } \\
\text { person } \\
(\mathrm{kg} / \mathrm{yr})\end{array}$} & Emission & present & 100.5 & 123.7 & 115.6 & 150.9 & 116.4 \\
\cline { 2 - 8 } & after EV & 73.9 & 100.2 & 79.9 & 128.8 & 87.9 \\
\hline
\end{tabular}

EV: electric vehicles.

\section{CONCLUSION}

The multinomial logit model is useful, because it helps us to understand the process of choice. This model allows us to calculate the utility using different variables of alternatives' and decision makers' attributes. We generalized this model for the combinations of direct product alternatives such as stores and transportation methods.

Using the proposed model, we clarified the structure of $\mathrm{CO}_{2}$ emission from food-buying shopping in a local city, and assessed the impact of introduction of 
micro EV. We estimated these $\mathrm{CO}_{2}$ emissions from personal behavior. This approach gives us only a gross estimate of $\mathrm{CO}_{2}$ emission, compared with detailed estimate from consumption levels of different fuels in the city. However, when we think how we can reduce the emission, this approach may be rewarding, because it is informative about why the emission occurs.

\section{ACKNOWLEDGMENTS}

The survey is performed as a part of a project "Construction of the town of Kiryu for the future with antiglobal-warming through the regional power" (Kiryu-80 project) supported by Research Institute of Science and Technology for Society (RISTEX) in Japan Science and Technology Agency.

\section{REFERENCES}

Ben-Akiva, M. E. and Lerman, S. R. (1985), Discrete Choice Analysis: Theory and Application to Travel Demand, MIT Press, Cambridge, MA.

Bertolini, L. and Clercq, F. I. (2003), Urban development without more mobility by car? Lessons from Amsterdam, a multimodal urban region, Environment and Planning $A, \mathbf{3 5}, 575-589$.

De Boncourt, M. (2011), The electric vehicle in the climate change race tortoise, hare or both? Institutfrancais des relations internationales, Paris, France, http://www.ifri.org/?page $=$ detail-contribution\&id $=6543 \&$ id $\_$provenance $=97$.

Hada, T. (2009), Hamamatsu smallest vehicle system project, Jidosha Gijyutsu, 63, 61-66.

Japan Automobile Manufacturers Association, Inc. (2011), Average fuel consumption of gasoline-engined car, http://www.jama.or.jp/eco/earth/earth_02_g03.html\#.

Ministry of Land, Infrastructure, Transport and Tourism (2010), Possibility and task of ultra small mobility, http://www.mlit.go.jp/common/000132670.pdf.

Ministry of the Environment (2011), List of emission rate of coefficients, http://www.env.go.jp/earth/ghg-sant eikohyo/material/itiran.pdf.

Toshio, H. (2011), Toward zero-emission mobility with solar energy and electric vehicle, Chemical Engineering of Japan, 75, 41-43.

Train, K. (2003), Discrete Choice Methods with Simulation, Cambridge University Press, New York, NY. 